\title{
Cancer Targets in the Ras Pathway
}

\author{
P. Rodriguez-Viciana, O. Tetsu, K. Oda, J. Okada, K. Rauen, \\ AND F. MCCORMICK \\ Cancer Research Institute, University of California San Francisco Comprehensive Cancer Center, \\ San Francisco, California 94115
}

\begin{abstract}
Ras proteins play a direct causal role in human cancer and in other diseases. Mutant H-Ras, N-Ras, and K-Ras occur in varying frequencies in different tumor types, for reasons that are not known. Other members of the Ras superfamily may also contribute to cancer. Mutations also occur in downstream pathways, notably B-Raf, PTEN, and PI 3' kinase: These pathways interact at multiple points, including cyclin D1, and act synergistically. In some cases mutations in Ras and effectors are mutually exclusive; in other cases, they coexist. Drugs blocking elements of the pathway are in different stages of clinical development. One of these, the Raf kinase/VEGF-R2 inhibitor Sorafenib, has already been approved for treatment of renal cancer and is being tested in other indications. However, therapeutic targets in the Ras pathway have not yet been fully validated as bona fide targets.
\end{abstract}

Mutant Ras proteins play a direct causal role in human cancer. Oncogenic mutant Ras proteins are resistant to down-regulation by GTPase activating proteins, and therefore remain in their active, GTP-bound state persistently (Bourne et al. 1991). Table 1 summarizes the frequency with which Ras mutations have been detected in primary human tumors and cancer-derived cell lines, using data from the Sanger Center COSMIC database www.sanger.ac.uk/genetics/CGP/cosmic/.
Although all three Ras genes, H-Ras, N-Ras, and KRas, occur in varying frequencies in different tumor types, $\mathrm{K}$-Ras is the form that is causally involved in the major cancers that afflict humans most frequently. The reasons for these differences have not been determined. The simplest interpretation is that these frequencies reflect levels of expression of proto-oncogenic forms and therefore reflect the relative contributions each protein makes to signal output. In support of this, mice lacking both H-Ras

Table 1. Ras Pathway Mutations in Human Cancer

\begin{tabular}{|c|c|c|c|c|c|c|c|}
\hline \multicolumn{8}{|c|}{$\%$ Positive samples } \\
\hline & EGF-R & HRAS & NRAS & KRAS & BRAF & PIK & PTEN \\
\hline Breast & 1 & 1 & 0 & 5 & 1 & 27 & 3 \\
\hline Large intestine & 0 & 1 & 2 & 31 & 15 & 24 & 9 \\
\hline Lung & 18 & 0 & 1 & 19 & 2 & 2 & 7 \\
\hline Prostate & 0 & 6 & 0 & 8 & 0 & 0 & 13 \\
\hline Autonomic ganglia & 0 & 0 & 8 & 3 & 1 & 0 & 2 \\
\hline Biliary tract & - & 0 & 1 & 33 & 15 & 0 & 0 \\
\hline Bone & 0 & 2 & 0 & 1 & 0 & 0 & 2 \\
\hline CNS & 0 & 0 & 2 & 3 & 5 & 5 & 19 \\
\hline Cervix & 0 & 10 & 2 & 9 & 0 & 0 & 6 \\
\hline Adrenal gland & - & 1 & 5 & 0 & 0 & 0 & 0 \\
\hline Endometrium & - & 1 & 0 & 14 & 1 & 50 & 34 \\
\hline Eye & - & 0 & 0 & 31 & 2 & 0 & 0 \\
\hline Heam/lymphoid & - & 0 & 12 & 4 & 2 & 0 & 4 \\
\hline Kidney & - & 0 & 0 & 1 & 15 & 0 & 4 \\
\hline Liver & 1 & 0 & 10 & 9 & 3 & 18 & 4 \\
\hline Esophagus & - & 1 & 0 & 2 & 3 & 0 & 1 \\
\hline Ovary & 0 & 0 & 3 & 18 & 16 & 6 & 5 \\
\hline Pancreas & 0 & 0 & 2 & 60 & 4 & 0 & 2 \\
\hline Salivary gland & - & 20 & 0 & 2 & 0 & 0 & 27 \\
\hline Skin & 0 & 6 & 16 & 2 & 44 & 0 & 13 \\
\hline Small intestine & 0 & 0 & 25 & 26 & 4 & 0 & 0 \\
\hline Soft tissue & 0 & 8 & 7 & 14 & 4 & 6 & 4 \\
\hline Stomach & 0 & 4 & 2 & 6 & 1 & 6 & 6 \\
\hline Testis & 0 & 0 & 4 & 5 & 0 & 0 & 0 \\
\hline Thyroid & - & 5 & 7 & 4 & 27 & 0 & 3 \\
\hline Urinary tract & - & 12 & 3 & 4 & 0 & 11 & 6 \\
\hline
\end{tabular}

These data were collected from the Sanger Center COSMIC database, December 2005 release. Frequencies of mutation in the four most common cancers are shown in the first four rows. 
and N-Ras are viable (Esteban et al. 2001), whereas mice lacking K-Ras are not (Johnson et al. 1997). However, we have found that all three Ras proteins are usually expressed within the same cell, at approximately the same level, suggesting that the three Ras proteins may have different functions which may be selected for during tumorigenesis in a tissue-specific fashion.

The first half of H-, K-, and N-Ras, which includes the switch 1 and 2 domains that are involved in interaction with effectors, are identical. Consistent with this, we have not found any difference in the ability of the three Ras proteins to interact with a comprehensive list of effectors. On the other hand, Ras proteins differ at the carboxyl terminus, a region involved in membrane localization, and indeed, $\mathrm{H}-, \mathrm{K}-$, and N-Ras have been found in different microdomains of the plasma membrane, as well as in different endomembrane compartments. Although the biological consequences of this differential localization are not yet clear, it is possible that the Ras proteins recruit their effectors and signal from different membrane compartments, and differences may be related to their characteristic mutational spectrum (Rodriguez-Viciana et al. 2004).

Recently, constitutional activating mutations in H-ras were detected in patients suffering from Costello syndrome, a complex developmental disorder characterized by craniofacial abnormalities, developmental delays, and a predisposition to neoplasia (Aoki et al. 2005; Estep et al. 2006; Gripp et al. 2006; Kerr et al. 2006). 34G to A transitions occur in $91 \%$ of affected individuals: This mutation was characterized previously as an activating allele of moderate transforming activity in focus-forming assays and occurs in human cancers. Less frequent mutations include $35 \mathrm{G}$ to $\mathrm{C}$ also in codon 12 , and $37 \mathrm{G}$ to $\mathrm{T}$ at codon 13 . In one case, it was possible to demonstrate loss of the normal H-Ras allele in a tumor that developed in a child suffering from this syndrome. Further analysis of biological and genetic attributes of this syndrome and related disorders may be informative in understanding specific functions of H-Ras in human development. Constitutional activating mutations have also been reported in the K-Ras gene in Noonan syndrome, a condition related to Costello syndrome (Schubbert et al. 2006). In these cases, K-Ras is activated by a mutation that is not fully transforming and is, in fact, partially sensitive to downregulation by GAP. Thus, individuals with fully activated H-Ras show a similar (although not identical) phenotype to those with a weak activated allele of K-Ras, confirming the suggestion that K-Ras is a more potent oncogene in vivo. Interestingly, part of the Ras pathway is activated by mutation in another syndrome, cardio-facial-cutaneous syndrome: In these individuals, activating mutations in B-Raf, MEK1, and MEK2 appear to be the cause of the disease (Rodriguez-Viciana et al. 2006). Interestingly, the mutations that activate B-Raf are generally not found in cancers, and indeed, these affected individuals are not cancer-prone. In addition, activating mutations in MEK1 and MEK2 have not been found in human cancers, although they appear to be fully active by preliminary biochemical analysis.

Structures of Ras proteins have been solved in several states: inactive, GDP-bound; active, bound to GppNHp (nonhydrolyzable GTP analog), position-12 mutant versions, complexes with exchange factors, GAPs, and effectors (Wittinghofer and Pai 1991). Despite this wealth of information, strategies for identifying Ras inhibitors have not been forthcoming. Considering the extremely high affinity of Ras proteins for GTP $\left(K_{\mathrm{d}}, 1 \mathrm{pM}\right)$ it seems unlikely that competitive inhibitors could be identified. Screens for small molecules that restore GTP hydrolysis of GTP bound to Ras failed to identify lead compounds, and analysis of high-resolution structures of mutant proteins suggested that this approach was doomed to fail. Activating substitutions were thought to present a steric block to GTP hydrolysis by preventing attack of $\gamma$-phosphate by a water molecule. This view has been revised recently: The structure of Ras bound in a transition state complexed with GDP.AlF4 and GAP suggests failure to hydrolyze GTP is the result of displacement of critical catalytic residues from GAP (the "arginine finger") rather than steric block. Consistent with this, a GTP analog in which an amino group is covalently attached to the $\gamma$ phosphate is hydrolyzed efficiently by mutant Ras proteins (Ahmadian et al. 1999). Whether this presents an opportunity for therapeutic intervention remains to be seen. Meanwhile, most approaches to blocking Ras activity depend on inhibition of downstream effectors rather than Ras itself. Considerable efforts expended on blocking Ras processing through farnesyl transferase were thwarted by the existence of a "back-up" modification that enables K-Ras to remain active through geranylgeranyl modification instead of farnesylation. However, several inhibitors have been developed extensively and tested in clinical trials. Since H-Ras is not geranylgeranylated in the absence of a farnesyl group, it is inhibited effectively by these compounds. Furthermore, H-Ras appears to be dispensable in normal tissues, at least in mice, suggesting that diseases driven by activated H-Ras would likely respond to these inhibitors without significant side effects on normal tissue.

\section{INCREASING COMPLEXITY OF Ras SIGNALING}

It was established in 1984 that Raf function was required for Ras transformation, and a direct interaction of Ras and Raf and mechanisms of Ras-dependent Raf activation were described in 1992 and thereafter. Very soon, however, it became apparent that Ras can also interact with and activate other effectors, including class I PI 3' kinase (PI3'K) and RalGEFs. Furthermore, Ras effectors were shown to act synergistically, implying that the full transforming potential of Ras depends on simultaneous activation of interacting downstream effector pathways (Fig. 1). Other Ras effectors identified from two-hybrid screens and other approaches include AF-6, RIN, PLCE, Nore1/Rassf5, IMP, and many others that await characterization (Rodriguez-Viciana et al. 2004). Analysis of mutations in human tumors has validated both the Raf and PI3' $\mathrm{K}$ pathways as crucial Ras effectors in human tumorigenesis (see below). However, data from a variety of experimental systems, including knock-out mice deficient for other effectors such as RalGDS, PLCE, and 


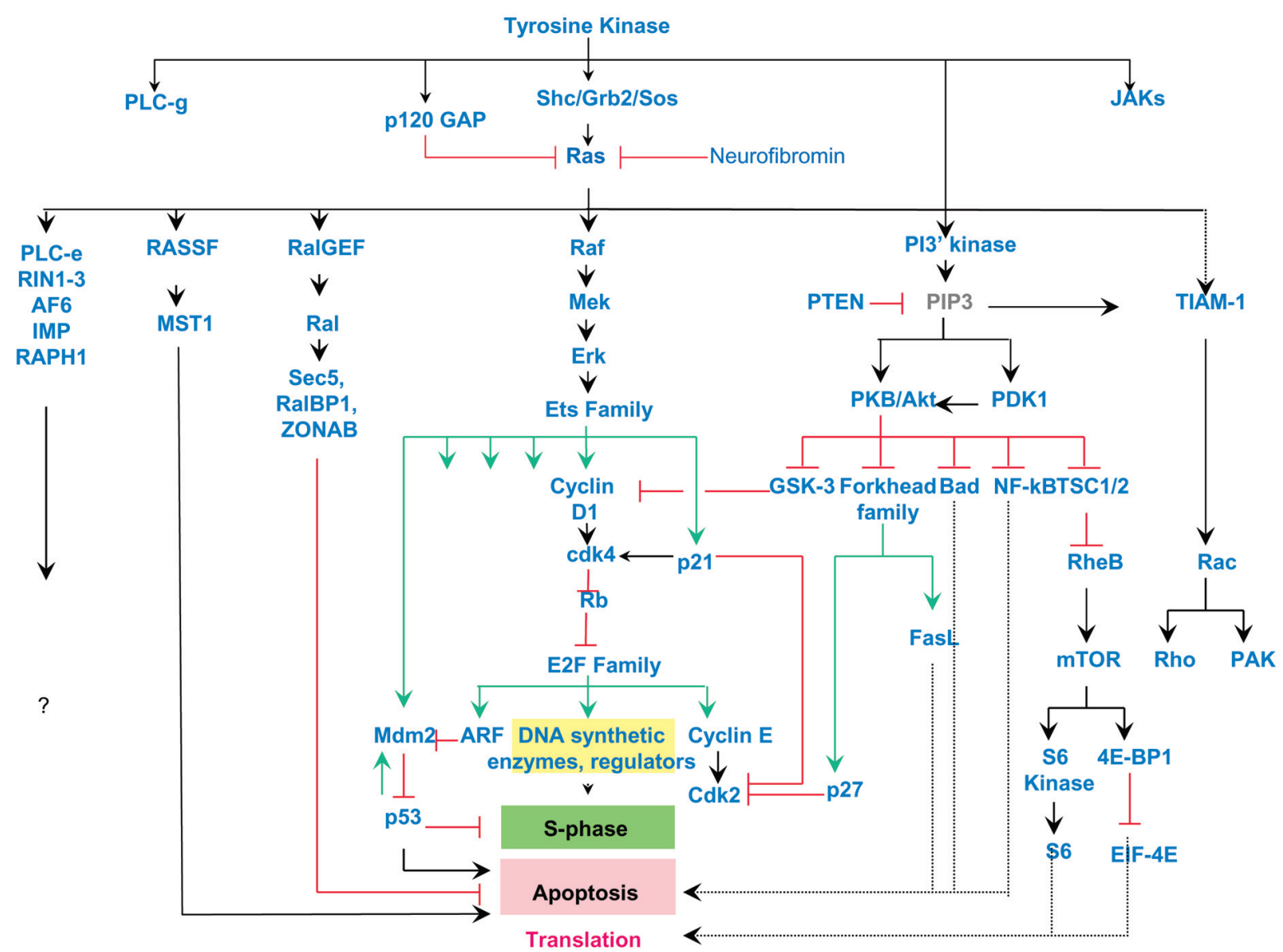

Figure 1. Signaling pathways downstream of Ras.

Tiam1, suggest that other effectors will likely make an important contribution to Ras-induced tumor formation. Activated Ras has been implicated in many of the properties of the malignant phenotype (i.e., uncontrolled proliferation, survival, invasion, and metastasis). It is likely that different effector pathways (or combinations of them) will contribute differentially to the various aspects of tumor biology in different cell types as well as during different stages of tumor progression.

In addition to the prototypic Ras proteins (H-, K-, and $\mathrm{N}$-Ras), the Ras family includes other closely related GTPases that share many of the biochemical and biological properties of Ras, including the ability to behave as oncogenes (Fig. 2). In particular, members of the R-Ras subgroup of the Ras family, which includes R-Ras, TC21/R-Ras2, and M-Ras/R-Ras3, have a high degree of overlap in their ability to interact with and regulate many of Ras known effectors. For example, H-, N-, and K-Ras, R-Ras, TC21, and M-Ras have similar abilities to activate the RalGEF family of effectors and the $\mathrm{p} 110 \alpha$ and $\gamma$ isoforms of class I PI3K. H-, N-, and K-Ras, on the other hand, are the strongest at interacting with and activating Raf kinases. R-Ras and TC21, however, are the only GTPases that can activate the p110 $\delta$ PI3K (RodriguezViciana et al. 2004). Individual GTPases have specific blueprints of effector interactions, and their signaling and biological properties should be considered in the context of the full spectrum of their many effector interactions.
With their ability to activate both the Raf and PI3K pathways, the R-Ras subgroup of Ras family GTPases may play a role in human cancer. In our hands, an activated L81 M-Ras mutant is as potent an oncogene as active Ras in a variety of classic transformation assays, and mutations in TC21 have already been found in a handful of human tumors (Rodriguez-Viciana et al. 2004). Determination of whether mutational activation of these GTPases is a rare or frequent way of deregulating the Ras pathway in tumors with wild-type Ras will have to await a comprehensive genetic analysis of human tumors, as has already been performed for other gene families. We have analyzed M-Ras sequences in a panel of 60 breast cancer cell lines and have so far failed to detect activating mutations in this gene (J. Gray and F. McCormick, unpubl.). A further degree of complexity is illustrated by our observation that, in some cases, Ras family GTPases can cross-talk to each other and cooperate in the activation of the same effector pathway. M-Ras, when activated, can target a phosphatase holoenzyme complex made up of Shoc 2 and the catalytic subunit of protein phosphatase 1 to remove a negative regulatory phosphate group from Raf kinase molecules complexed with active Ras proteins, thereby further stimulating Raf-specific activity (Fig. 3). Importantly, Shoc2 function is essential for ERK activity in tumor cells with mutant Ras, and therefore, the Shoc2-PP1C holoenzyme represents an additional target for pharmacological inhibition of the ERK pathway (P. 


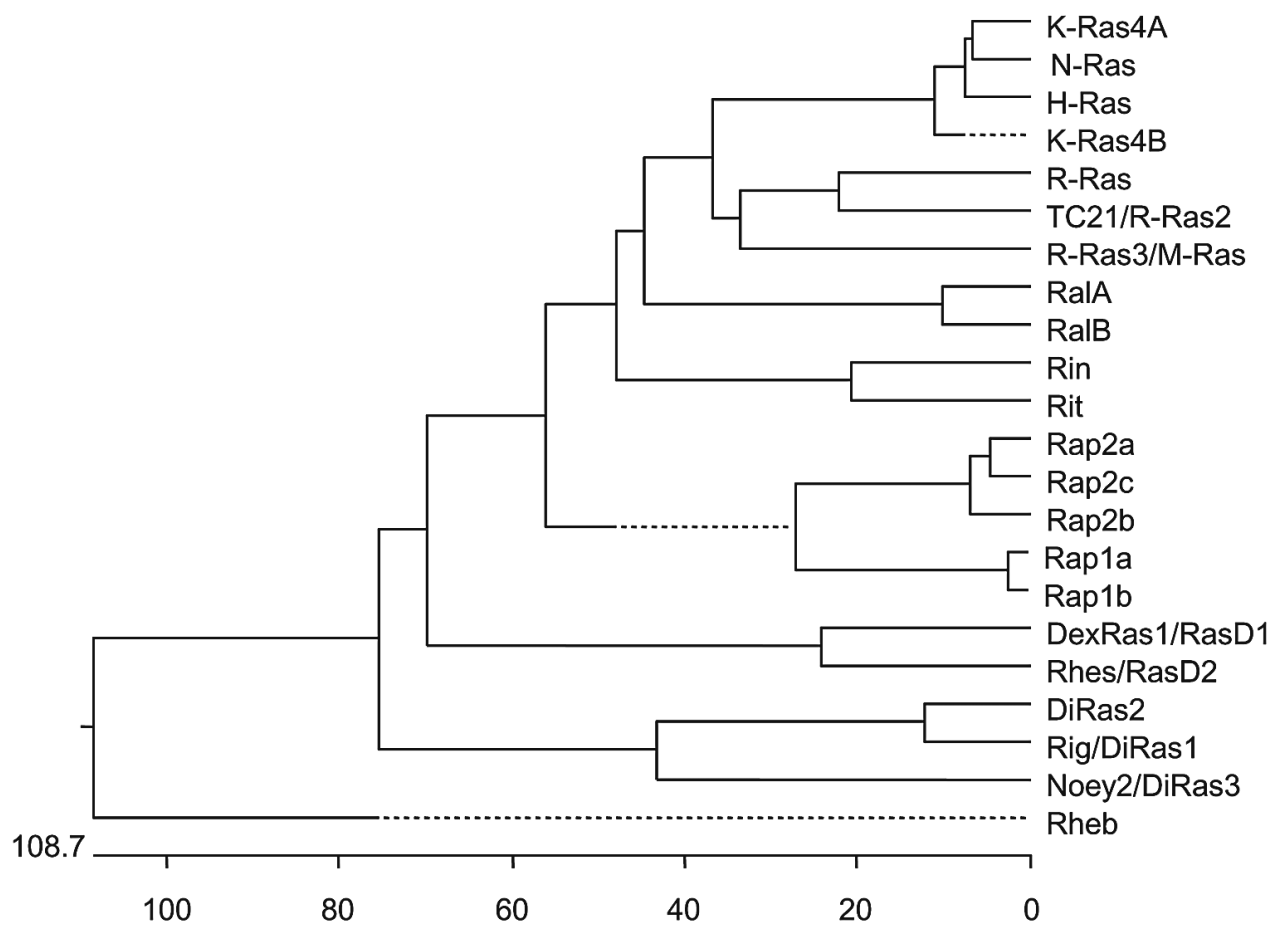

Figure 2. The Ras superfamily of small GTPases.

Rodriguez-Viciana and F. McCormick, in prep.). Clearly, a better understanding of the many effector pathways regulated by Ras and its closely related GTPases will likely lead to the identification of novel targets of therapeutic intervention in human cancer.

\section{CANCER GENETICS AND RAS EFFECTORS}

Until recently, the PI 3 'K pathway appeared to be the more critical Ras effector pathway in human cancer, based on the observation that mutations occur frequently in major regulators of this pathway, including
PI3' $\mathrm{K}$ itself and the lipid phosphate PTEN. Activating mutations in Akt2, PDK1, and PAK4 have also been reported at lower frequency. In 2002, frequent activation of B-Raf was reported in many types of human cancer, most notably malignant melanoma (Davies et al. 2002). This discovery confirmed the importance of the MAPK pathway in cancer and encouraged development of drugs that target enzymes in the pathway. In addition, the coexistence of mutations in the Ras pathway in human tumors has led to new insights relating to signal cross-talk and codependence. For example, activating mutations in N-Ras are mutually exclusive with muta-

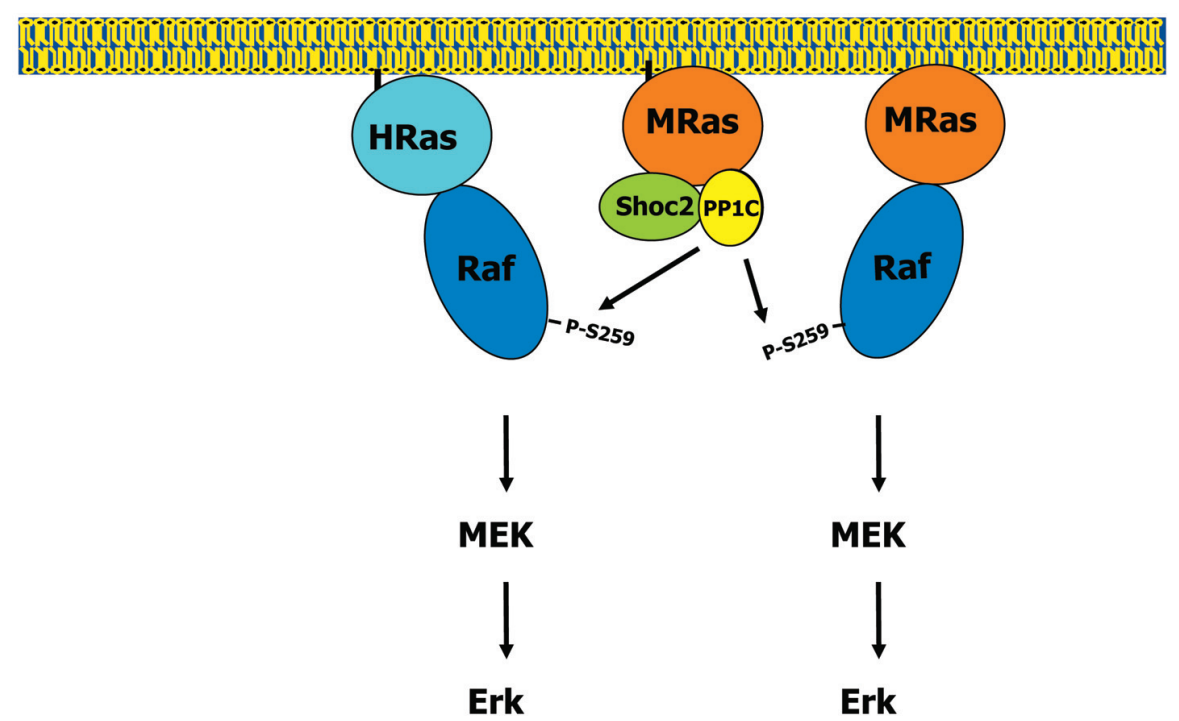

Figure 3. Model for the action of R-Ras3 (M-Ras) on Raf kinase, through recruitment of SHOC-2/PP1C complexes to the plasma membrane. 
tions in PTEN in this disease, and also with mutations in B-Raf. This suggests that both major Ras effector arms need to be activated to sustain the malignant phenotype, and that the combined effect of activated MAPK and PI3' $\mathrm{K}$ can be achieved by a single mutation in N-Ras, or two independent mutations in B-Raf and PTEN. These two pathways may converge at several key points: For example, p27 expression is increased by hyperactivation of MAPK, potentially leading to growth arrest. However, the PI3'K pathway targets p27 for degradation. These observations suggest an obvious molecular basis for coactivation of these pathways. Another point of intersection may be cyclin D1. Transcription of cyclin D1 is regulated by the MAPK pathway, but cyclin D1 protein is stabilized by the PI3' K pathway; high levels of cyclin D1 protein obviously need inputs from both signaling pathways. Consistent with a role for cyclin D1 in malignant melanoma, this gene is amplified in rare forms of melanoma in which Ras, B-Raf, and PTEN are wild type (Bastian et al. 2001).

Transcriptional regulation of cyclin D1 involves several different types of transcription factors such as AP-1/c-Jun (Albanese et al. 1995; Bakiri et al. 2000), CREB (Tetsu and McCormick 1999), NF-кB (Guttridge et al. 1999; Hinz et al. 1999), and c-Ets (Albanese et al. 1995; Tetsu and McCormick 1999). In addition, we showed that cyclin $\mathrm{D} 1$ is a major transcriptional target of the APC/ $\beta$ catenin/TCF signaling pathway (Tetsu and McCormick 1999; Hulit et al. 2004; Lepourcelet et al. 2004). Increased expression of cyclin D1 protein therefore depends on hyperactive signals from a number of pathways. Stabilization of the protein through activation of the PI3' $\mathrm{K}$ pathway has also been reported, suggesting that signals both from the RAF/MEK/ERK pathway, leading to transcriptional activation, and from the PI3' $\mathrm{K}$ pathway, leading to posttranscriptional activation, may be necessary: A similar situation has been described for Mdm2, in which the RAF/MEK/ERK pathway increases transcription, and the PI3'K pathway leads to stabilization.

In contrast to the relatively simple relationship between Ras and its major effectors in melanoma, mutations in K-Ras, PTEN, and PI3' K coexist in other types of cancer: Mutations in K-Ras and PI3'K often coexist in colon cancer, for example. We have analyzed mutations in the PIK3CA gene in 66 endometrial carcinoma patients. We identified coexistence of PTEN and PIK3CA mutations in 26\% (17/66) of patients (Oda et al. 2005). Tumors with PTEN mutation showed a tendency to carry PIK3CA mutation more frequently $(17 / 37=46 \%)$ than tumors without PTEN mutation $(7 / 29=24 \%)$, although statistical significance was not reached $(p=0.078$ in Fisher's exact test). Subsequently, we evaluated the relationship between PIK3CA mutation and other clinicopathological factors. There was no evidence of an association of PIK3CA mutations with histological grade, FIGO stage, lymph node metastasis, and ER/PgR status. These data are in striking contrast to those of breast carcinoma, showing that PIK3CA mutations correlate with expression of hormone receptors and node metastasis, and are mutually exclusive with loss of PTEN expression. However, 2/8 (25\%) PTEN mutant breast carcinomas also possessed $P I K 3 C A$ mutations, suggesting that coexistence of PTEN/PIK3CA mutations could occur in other tumors as well (Oda et al. 2005).

Coexistence of mutations in both PTEN and PIK3CA may imply that more than one input activating the $\mathrm{PI} 3 \mathrm{~K} / \mathrm{Akt}$ pathway is required to completely activate this pathway in endometrial cancers, but not in melanoma. In breast carcinoma, PIK3CA mutations correlate with ErbB2 overexpression, suggesting that another activating event may be necessary to fully activate the PI3K pathway. Alternatively, either PTEN or $\mathrm{p} 110 \alpha$ may possess additional function(s) distinct from the PI3K pathway.

\section{DEVELOPMENT OF SORAFENIB/NEXAVAR, A Raf KINASE INHIBITOR}

In 1992, the drug discovery group at ONYX Pharmaceuticals screened a library of compounds for inhibitors of Raf-1 kinase activity. As a source of active kinase for this screen, Raf-1 was expressed in Sf9 cells using baculovirus vectors. The protein had been engineered with an epitope tag to facilitate purification, and cells were co-infected with a vector expressing v-src to activate Raf-1 kinase. A compound that was selective for Raf-1 was identified and a medicinal chemistry program was initiated to identify derivatives with improved properties. The compound shown in Figure 4, first referred to as BAY43-9006, then Sorafenib, entered Phase I clinical trials in 2000. At that time, it was assumed that inhibition of Raf kinase in cancer cells would reverse aspects of the transformed phenotype. This assumption was based on experimental systems in which Raf kinase was inhibited using microinjected antibodies or dominant negative constructs. These approaches suggested that Raf kinase is an appropriate target for intervention, but did not predict side effects through Raf inhibition in normal tissue, and did not predict the consequences of blocking Ras in cancers in vivo. Furthermore, it was not clear whether Raf kinase is activated in tumors that do not harbor oncogenic Ras alleles. For these reasons, Phase I trials were launched for all types of cancers, without bias toward cancers with high frequencies of Ras mutation. During these trials, stabilization of disease was noted in patients suffering from renal cell carcinoma, a disease with no obvious association with activated Raf kinase. At this time, the specificity of Sorafenib/Nexavar was scrutinized, and a potent effect on VEGF-R2 was observed: This may well account for clinical effects in renal cell carcinoma, since this disease is associated with activated VEGF signaling through loss of the VHL tumor suppressor (Wilhelm et al. 2004). After completion in 2005 of a successful Phase III trial, in which a significant improvement in time to progression was reported, Nexavar was approved in the U.S. for treatment of metastatic renal cell carcinoma (Fig. 5).

In 2002, existence of BRAF mutations in human cancers was first reported. Activation frequencies approaching 70\% were detected in malignant melanoma, and significant frequencies in several other human cancers (Davies et al. 2002). On the basis of these discoveries, 
<smiles>COC(=O)c1sc(C(C)(C)C)cc1NC(=O)Nc1ccccc1</smiles>

BAY $43-9006$

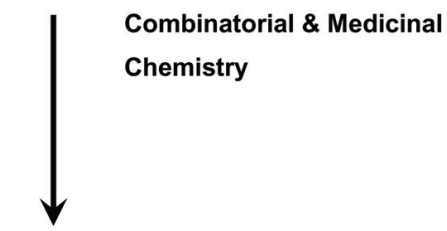

IC50: $12 \mathrm{nM}$, oral activity in animals<smiles>CNC(=O)c1cc(Oc2ccc(NC(=O)Nc3ccc(Cl)c(C(F)(F)F)c3)cc2)ccn1</smiles>

Phase I clinical trials, July $\mathbf{2 0 0 0}$

Figure 4. Structure of the lead compound identified in a screen for Raf kinase inhibitors, and structure of Sorafenib.

clinical trials were initiated in which Nexavar was tested in patients suffering from malignant melanoma. To date, little clinical activity has been observed as a single agent, however, even though the drug appeared to hit the target effectively, i.e., MEK phosphorylation was blocked significantly. Lack of efficacy could be because (1) late-stage melanomas may no longer be Raf-dependent; (2) Raf inhibition causes growth arrest, but not apoptosis; or (3) the drug is not potent enough. Relating perhaps to the second point, BRAF mutations frequently coexist with PTEN mutations, as described above. Loss of PTEN has been reported to render other targeted therapies ineffective, presumably because cells in which PI3'K has been up-regulated are more difficult to kill. Nevertheless, Nexavar is currently being tested in combination therapies and as a single agent in multiple disease indications. However, the clinical value of blocking the Ras or Raf pathway remains uncertain.

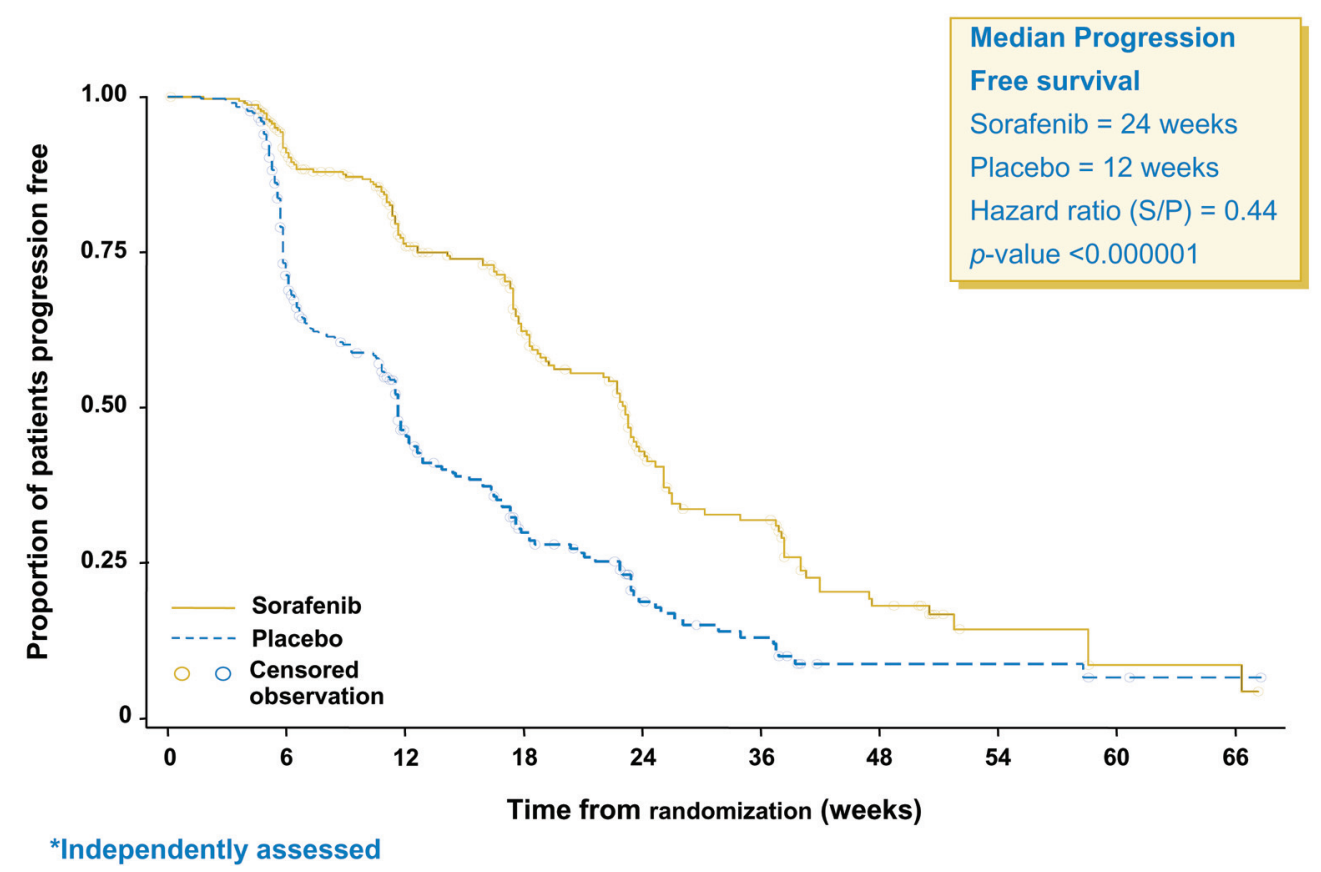

Figure 5. Increased survival in patients treated with Sorafenib/Nexavar as an orally active single agent, in patients suffering from renal cell carcinoma. 


\section{CONCLUSIONS}

Ras proteins and their downstream effectors play direct causal roles in human cancer. Analysis of mutations in these pathways reveals that the MAPK pathway and the PI3K pathways are activated frequently in cancers, in addition to K-Ras, and, to a lesser degree, N-Ras and H-Ras. To date, only one drug (Nexavar) targeting the Ras pathway has been approved for cancer treatment, but a number of others are under development. The clinical value of targeting these pathways remains unclear, since Nexavar was approved for treatment of renal cell cancer based, most likely, on its activity against VEGF-R2 rather than Raf kinase. However, we expect that single agents and combinations of agents targeting key enzymes in these pathways will play a powerful role in cancer treatment in the future, and that their successful clinical development will depend on a clear understanding of the complexities of the entire Ras pathway.

\section{REFERENCES}

Ahmadian M.R., Zor T., Vogt D., Kabsch W., Selinger Z., Wittinghofer A., and Scheffzek K. 1999. Guanosine triphosphatase stimulation of oncogenic Ras mutants. Proc. Natl. Acad. Sci. 96: 7065.

Albanese C., Johnson J., Watanabe G., Eklund N., Vu D., Arnold A., and Pestell R.G. 1995. Transforming p21ras mutants and c-Ets-2 activate the cyclin D1 promoter through distinguishable regions. J. Biol. Chem. 270: 23589.

Aoki Y., Niihori T., Kawame H., Kurosawa K., Ohashi H., Tanaka Y., Filocamo M., Kato K., Suzuki Y., Kure S., and Matsubara Y. 2005. Germline mutations in HRAS protooncogene cause Costello syndrome. Nat. Genet. 37: 1038.

Bakiri L., Lallemand D., Bossy-Wetzel E., and Yaniv M. 2000. Cell cycle-dependent variations in c-Jun and JunB phosphorylation: A role in the control of cyclin D1 expression. EMBO J. 19: 2056.

Bastian B.C., LeBoit P.E., and Pinkel D. 2001. Genomic approaches to skin cancer diagnosis. Arch. Dermatol. 137: 1507.

Bourne H.R., Sanders D.A., and McCormick F. 1991. The GTPase superfamily: Conserved structure and molecular mechanism. Nature 349: 117 .

Davies H., Bignell G.R., Cox C., Stephens P., Edkins S., Clegg S., Teague J., Woffendin H., Garnett M.J., Bottomley W., Davis N., Dicks E., Ewing R., Floyd Y., Gray K., Hall S., Hawes R., Hughes J., Kosmidou V., Menzies A., Mould C., Parker A., Stevens C., Watt S., Hooper S., Wilson R., Jayatilake H., Gusterson B.A., Cooper C., Shipley J., Hargrave D., Pritchard-Jones K., Maitland N., Chevenix-Trench G., Riggins G.J., Bigner D.D., Palmieri G., Cossu A., Flanagan A., Nicholson A., Ho J.W., Leung S.Y., Yuen S.T., Weber B.L., Seigler H.F., Darrow T.L., Paterson H., Marais R., Marshall C.J., Wooster R., Stratton M.R., and Futreal P.A. 2002. Mutations of the BRAF gene in human cancer. Nature 417: 949.

Esteban L.M., Vicario-Abejon C., Fernandez-Salguero P., Fernandez-Medarde A., Swaminathan N., Yienger K., Lopez E., Malumbres M., McKay R., Ward J.M., Pellicer A., and Santos E. 2001. Targeted genomic disruption of H-ras and N-ras, individually or in combination, reveals the dispensability of both loci for mouse growth and development. Mol. Cell. Biol. 21: 1444.

Estep A.L., Tidyman W.E., Teitell M.A., Cotter P.D., and Rauen K.A. 2006. HRAS mutations in Costello syndrome: Detection of constitutional activating mutations in codon 12 and 13 and loss of wild-type allele in malignancy. Am. J. Med. Genet. A 140: 8 .

Gripp K.W., Lin A.E., Stabley D.L., Nicholson L., Scott C.I., Jr., Doyle D., Aoki Y., Matsubara Y., Zackai E.H., Lapunzina P., Gonzalez-Meneses A., Holbrook J., Agresta C.A., Gonzalez I.L., and Sol-Church K. 2006. HRAS mutation analysis in Costello syndrome: Genotype and phenotype correlation. Am. J. Med. Genet. A 140: 1.

Guttridge D.C., Albanese C., Reuther J.Y., Pestell R.G., and Baldwin A.S., Jr. 1999. NF-kappaB controls cell growth and differentiation through transcriptional regulation of cyclin D1. Mol. Cell. Biol. 19: 5785.

Hinz M., Krappmann D., Eichten A., Heder A., Scheidereit C., and Strauss M. 1999. NF-kappaB function in growth control: Regulation of cyclin D1 expression and G0/G1-to-S-phase transition. Mol. Cell. Biol. 19: 2690.

Hulit J., Wang C., Li Z., Albanese C., Rao M., Di Vizio D., Shah S., Byers S.W., Mahmood R., Augenlicht L.H., Russell R., and Pestell R.G. 2004. Cyclin D1 genetic heterozygosity regulates colonic epithelial cell differentiation and tumor number in ApcMin mice. Mol. Cell. Biol. 24: 7598.

Johnson L., Greenbaum D., Cichowski K., Mercer K., Murphy E., Schmitt E., Bronson R.T., Umanoff H., Edelmann W., Kucherlapati R., and Jacks T. 1997. K-ras is an essential gene in the mouse with partial functional overlap with N-ras. Genes. Dev. 11: 2468.

Kerr B., Delrue M.A., Sigaudy S., Perveen R., Marche M., Burgelin I., Stef M., Tang B., Eden T., O'Sullivan J., De Sandre-Giovannoli A., Reardon W., Brewer C., Bennett C., Quarrell O., McCann E., Donnai D., Stewart F., Hennekam R., Cave H., Verloes A., Philip N., Lacombe D., Levy N., Arveiler B., and Black G. 2006. Genotype-phenotype correlation in Costello syndrome; HRAS mutation analysis in 43 cases. J. Med. Genet. (in press).

Lepourcelet M., Chen Y.N., France D.S., Wang H., Crews P., Petersen F., Bruseo C., Wood A.W., and Shivdasani R.A. 2004. Small-molecule antagonists of the oncogenic Tcf/betacatenin protein complex. Cancer Cell 5: 91.

Oda K., Stokoe D., Taketani Y., and McCormick F. 2005. High frequency of coexistent mutations of PIK3CA and PTEN genes in endometrial carcinoma. Cancer Res. 65: 10669.

Rodriguez-Viciana P., Sabatier C., and McCormick F. 2004. Signaling specificity by Ras family GTPases is determined by the full spectrum of effectors they regulate. Mol. Cell. Biol. 24: 4943.

Rodriguez-Viciana P., Tetsu O., Tidyman W.E., Estep A.L., Conger B.A., Santa Cruz M., McCormick F., and Rauen K.A. 2006. Germline mutations in genes within the MAPK pathway cause cardio-facio-cutaneous syndrome. Science 311: 1287.

Schubbert S., Zenker M., Rowe S.L., Boll S., Klein C., Bollag G., van der Burgt I., Musante L., Kalscheuer V., Wehner L.E., Nguyen H., West B., Zhang K.Y., Sistermans E., Rauch A., Niemeyer C.M., Shannon K., and Kratz C.P. 2006. Germline KRAS mutations cause Noonan syndrome. Nat. Genet. 38: 331.

Tetsu O. and McCormick F. 1999. Beta-catenin regulates expression of cyclin D1 in colon carcinoma cells. Nature 398: 422.

Wilhelm S.M., Carter C., Tang L., Wilkie D., McNabola A., Rong H., Chen C., Zhang X., Vincent P., McHugh M., Cao Y., Shujah J., Gawlak S., Eveleigh D., Rowley B., Liu L., Adnane L., Lynch M., Auclair D., Taylor I., Gedrich R., Voznesensky A., Riedl B., Post L.E., Bollag G., and Trail P.A. 2004. BAY 43-9006 exhibits broad spectrum oral antitumor activity and targets the RAF/MEK/ERK pathway and receptor tyrosine kinases involved in tumor progression and angiogenesis. Cancer Res. 64: 7099.

Wittinghofer A. and Pai E.F. 1991. The structure of Ras protein: A model for a universal molecular switch. Trends Biochem. Sci. 16: 382. 


\section{$8_{8}^{\infty} \mathrm{CSH} \&$ Cold Spring Harbor Symposia SYMPOSIA on Quantitative Biology}

\section{Cancer Targets in the Ras Pathway}

P. RODRIGUEZ-VICIANA, O. TETSU, K. ODA, et al.

Cold Spring Harb Symp Quant Biol 2005 70: 461-467

Access the most recent version at doi:10.1101/sqb.2005.70.044

References This article cites 22 articles, 12 of which can be accessed free at: http://symposium.cshlp.org/content/70/461.full.html\#ref-list-1

\section{License}

Email Alerting Receive free email alerts when new articles cite this article - sign up in Service the box at the top right corner of the article or click here. 